\title{
Entre o cinismo e a hipocrisia: o novo ciclo de reformas educacionais no Brasil
}

\section{Between cynicism and hypocrisy: the new cycle of educational reforms in Brazil}

\author{
Eduardo Donizeti Girotto*
}

\begin{abstract}
RESUMO
Estamos diante de um novo ciclo de reformas educacionais no Brasil, concebido a partir de uma lógica de controle técnico, burocrático e gerencial do trabalho docente, que retoma processos colocados em prática nas décadas de 1980 e 1990 em diversas partes do mundo. Com o intuito de compreender os agentes, os interesses e as estratégias presentes neste novo ciclo, analisamos documentos publicados por organismos internacionais e institutos financiados por grupos empresariais, com atuação no Brasil e no mundo, que têm lugar de destaque na elaboração das atuais políticas educacionais. $\mathrm{Na}$ análise realizada, verificamos que o objetivo é a contenção dos investimentos diretos em educação pública. Para tanto, propõem-se mudanças na forma de contratação e organização das carreiras docentes no país, consideradas responsáveis pela crise orçamentária brasileira. As análises demonstraram a importância de compreender quem são os principais agentes do novo ciclo de reformas educacionais, bem como os interesses que expressam. Trata-se de ação fundamental na luta pela construção de uma escola pública equitativa e democrática no Brasil que passa pela ampliação dos investimentos com o intuito de garantir as condições fundamentais para a ação educativa.

Palavras-chave: Reformas Educacionais. Trabalho Docente. Banco Mundial. Eficiência. Gestão.
\end{abstract}

\footnotetext{
ABSTRACT

We are facing a new cycle of educational reforms in Brazil, conceived on the basis of technical, bureaucratic and managerial control of the teacher's job, taking up processes put into practice in the 1980s and 1990s in various

* Universidade de São Paulo. São Paulo, São Paulo, Brasil. E-mail: egirotto@usp.br. https:// orcid.org/0000-0002-9870-6188.
} 
parts of the world. In order to understand the agents, interests and strategies present in this new cycle, we analyze documents published by international organizations and institutes financed by business groups, operating in Brazil and worldwide, prominent in the elaboration of current educational policies. In this analysis, we have verified that the objective is the containment of direct investments in public education. Therefore, changes are proposed in the form of hiring and organization of teaching careers in the country, considered responsible for the Brazilian budget crisis. The analyses have demonstrated the importance of understanding who are the main players in the new cycle of educational reforms, as well as the interests they express. This is fundamental in the struggle for the construction of an equitable and democratic publicschool system in Brazil involving the expansion of investments in order to guarantee the fundamental conditions for educational action.

Keywords: Educational Reforms. Teaching. World Bank. Efficiency. Management.

\section{Introdução}

Rede estadual de SP enfrenta saída recorde de professores Folha de São Paulo, 17/11/2015

A manchete anterior foi publicada no principal jornal escrito do Brasil e revela uma das mais perversas dimensões das políticas públicas de educação postas em prática nos últimos 20 anos no estado de São Paulo: a destruição da carreira docente e o seu abandono por professores atuais e futuros. Baseada em uma lógica gerencialista, de controle técnico e burocrático das diferentes ações docentes (APPLE, 2006), que resultaram no achatamento de salários e na falta de perspectiva em relação às condições de carreira atuais e futuras, tal política tem diminuído o interesse dos futuros professores e professoras pela rede estadual de educação de São Paulo.

Pautados na ideia de avaliação e responsabilização, as políticas da rede estadual de educação têm criado processos nos quais os docentes aparecem como os principais (se não, os únicos) responsáveis pelo desempenho dos estudantes em testes padronizados, em especial, o Sistema de Avaliação de Rendimento do Estado de São Paulo (SARESP), criado em 1996. A política de responsabilização docente tem como principal objetivo ocultar a responsabilidade dos outros sujeitos da educação pública, em especial, o governo do Estado, que assim continua a não realizar os investimentos necessários para criar as condições materiais para o desenvolvimento da ação educativa. 
No entanto, apesar do fracasso educacional da rede estadual de São Paulo verificada pela saída de professores, pelo baixo aproveitamento dos estudantes no que se refere à capacidade de leitura, de realização de cálculos, de compreensão crítica e significativa dos fenômenos naturais, sociais e de suas interrelações, pelas condições de infraestrutura (ou da falta dela) das escolas - os gestores dessas políticas foram alçados à posição de destaque no cenário nacional, ocupando cargos no Ministério da Educação. O que, a princípio, poderia se configurar uma contradição, observando-se o detalhe, expressa-se como a continuidade de um projeto que visa construir um modelo de educação economicamente viável à luz das atuais disputas pelo orçamento público. Tal lógica de contenção dos investimentos em educação está no centro do atual ciclo de reformas educacionais que vem sendo postas em prática na América Latina nos últimos anos. Trata-se de uma lógica construída a partir de uma nova concertação política, na qual se destacam, como principais agentes, o empresariado transnacional e as diferentes organizações criadas, por eles mesmos, para difundir um discurso com vistas a elencar os princípios da nova gestão pública como modelo a ser seguido na educação em suas diferentes escalas de realização.

No caso brasileiro, grupos como Instituto Airton Senna, Fundação Lehman, Instituto Alfa e Beto, Todos pela Educação e Instituto Itaú Unibanco são os principais interlocutores das reformas educacionais, fazendo a mediação entre os órgãos do governo (MEC, Secretarias Estaduais e Municipais), com o empresariado transnacional e os seus organismos representantes (Organização para Cooperação e Desenvolvimento Econômico - OCDE, Banco Mundial, Fundação Melina e Bill Gates). Por meio dessa mediação, seus interesses têm avançado nas políticas educacionais que representam o setor, expressos em documentos publicados em seus sites. Por isso, necessitam da indicação de nomes alinhados com essa lógica para ocupar postos estratégicos de decisão e de elaboração das políticas de educação. Em certa medida, isto explica a nomeação da ex-secretária estadual de educação de São Paulo, Maria Helena Guimarães Castro, uma das responsáveis pelo caos que vive a rede atualmente, para o cargo de Secretária Executiva do MEC. A secretária encontra-se profundamente alinhada com a lógica de controle gerencial e burocrática das políticas educacionais, pautada na dupla avaliação e responsabilização docente.

É importante destacar que a nomeação de pessoas vinculadas aos interesses do setor empresarial e dos organismos internacionais para cargos do Ministério da Educação e dos órgãos a ele subordinados não é uma novidade. Já é prática recorrente, há, pelo menos, duas décadas, e não foi rompida com a chegada ao poder do Partido dos Trabalhadores. Ao contrário, o que nos traz maior preocupação, é que tais grupos ganharam espaço durante os governos de Lula e Dilma, passando a influenciar cada vez mais os rumos das políticas educacionais brasi- 
leiras. Trata-se de mais uma face do discurso de conciliação de classes adotado pelos governos do PT e que, como demonstra a atual crise política, resultaram na própria desconstrução do partido como força progressista da política brasileira.

No entanto, não é possível compreender o papel desempenhado por estes grupos na condução das políticas educacionais se não entendermos as relações mais amplas entre educação e economia no interior do modo de produção capitalista, considerando as especificidades da formação socioespacial brasileira. Só com o entendimento do que significa o estado nacional brasileiro, no qual o orçamento é disputado o tempo todo por agentes das mais diferentes escalas espaço-temporais, é que poderemos compreender por que o empresariado transnacional busca, a todo momento, intervir nos rumos das políticas educacionais, em suas mais diferentes dimensões.

Dessa forma, apresentamos, neste texto, a análise construída a partir das leituras de alguns documentos publicados por esses grupos e institutos e que expressam suas posições acerca das concepções que devem nortear as reformas educacionais no Brasil e no mundo. Apresentamos, na Tabela 1, os documentos analisados neste texto:

\section{TABELA 1 - DOCUMENTOS ANALISADOS}

\begin{tabular}{|c|c|c|}
\hline Texto & Autores & $\begin{array}{c}\text { Ano de } \\
\text { Publicação }\end{array}$ \\
\hline $\begin{array}{c}\text { Identifying effective teachers using } \\
\text { performance on the job }\end{array}$ & $\begin{array}{c}\text { GORDON, R.; KANE, T.; } \\
\text { STAIGER, D. }\end{array}$ & 2006 \\
\hline $\begin{array}{c}\text { Achieving world class education in Brazil: the } \\
\text { next agenda }\end{array}$ & Banco Mundial & 2010 \\
\hline $\begin{array}{c}\text { Professores excelentes: como melhorar a } \\
\text { aprendizagem dos estudantes na } \\
\text { América Latina e no Caribe }\end{array}$ & Banco Mundial & 2014 \\
\hline $\begin{array}{c}\text { Competências para o progresso social: o poder das } \\
\text { competências socioemocionais }\end{array}$ & $\begin{array}{c}\text { OCDE / Instituto Airton } \\
\text { Senna / Fundação Santillana }\end{array}$ & 2015 \\
\hline $\begin{array}{c}\text { Construindo uma educação de qualidade: um } \\
\text { pacto com o futuro da América Latina / Comissão } \\
\text { para a Educação de Qualidade para Todos }\end{array}$ & Instituto Airton Senna & 2016 \\
\hline
\end{tabular}

FONTE: elaborado pelo autor, 2017.

Como dissemos, a escolha dos referidos documentos está diretamente articulada ao papel que os seus elaboradores desempenham na construção das atuais políticas educacionais no país. As ideias ali defendidas, como demonstraremos no decorrer deste trabalho, estão no centro de medidas anunciadas e executadas nas últimas décadas, com implicações amplas para a precarização do trabalho docente. 


\section{A disputa pelo orçamento e lógica gerencial da educação}

Iniciamos a análise pelo documento Achieving world class education in Brazil: the next agenda), publicado pelo Banco Mundial em 2010. Não se trata do mais antigo na lista dos documentos analisados, mas possui uma centralidade nas proposições do novo ciclo de reforma educacional, uma vez que seus principais argumentos são citados e retomados nos outros documentos. Além disso, é o único documento entre os analisados que se refere, especificamente, à realidade brasileira.

Nesse material, está explícita a compreensão de que o principal desafio para os próximos governos brasileiros (daí o documento se referir ao termo "próxima agenda") é diminuir o custo da educação no país. No documento, a principal causa de aumento de tais custos é atribuída aos gastos com salários docentes, considerados altos demais, configurando-se como peso excessivo nos orçamentos públicos nas diferentes esferas de governo. Segundo o documento, a situação orçamentária teria piorado na última década em decorrência de contínuos aumentos salariais dos professores, em uma crítica indireta a Lei do Piso aprovado em 2008'. Entre as soluções propostas pelo Banco Mundial para a resolução desse problema estão as mudanças na carreira docente e na contratação de professores, facilitando o ingresso na carreira de profissionais não formados na área, aumento do número de alunos por salas e alterações na formação inicial dos professores, como cursos de treinamento rápido.

As proposições feitas pelo Banco Mundial no documento de 2010 vêm sendo retomadas em outros documentos publicados pelo Banco e por outras instituições, reforçando o argumento do alto custo da educação no Brasil. Em tais documentos, reforça-se a ideia da busca pela eficiência e pelo aprimoramento da gestão apontadas como soluções. Certos documentos, como o publicado em 2016 pelo Instituto Airton Senna, em parceria com a Fundação Santillana - uma das maiores empresas transnacionais de livros didáticos, com ampla atuação na América Latina (Construindo uma educação de qualidade: um pacto com o futuro da América Latina) -, fala-se em manejo de sala de aula, concepção que reduz a complexidade do trabalho docente à sua dimensão instrumental.

1 Sancionada em 16 de julho de 2008, a Lei $\mathrm{n}^{\circ} 11.738$ institui o piso salarial profissional para os profissionais do magistério público da educação básica. Resultado da pressão dos sindicatos docentes, a lei estabelece uma política de reajuste salarial com vistas a equiparar, em médio prazo, o salário docente com os de outros profissionais com o mesmo tempo de escolaridade. Desde que entrou em vigor, o piso salarial docente aumentou $142 \%$, chegando, em 2017 , ao valor de R\$ $2.298,80$ para uma jornada de 40 horas semanais. 
Segundo o documento, além dos aumentos salariais, outros dois fatores seriam responsáveis pelo aumento do peso dos salários docentes sobre os orçamentos públicos: o número pequeno de alunos por sala de aula e a alta exigência de formação para ingressar na carreira. É interessante notar que, em relação ao primeiro aspecto citado, há uma contradição entre o documento do Banco Mundial e o relatório Education at a Glance da OCDE, publicado em 2016, que aponta que o número de alunos por professores no Brasil é o mais alto da América Latina. É importante ressaltar que este equívoco do documento não pode ser tomado como um equívoco, uma vez que esta concepção tem norteado ações de diferentes redes de educação no Brasil, como o projeto de reorganização escolar apresentado pelo governo de São Paulo em setembro de 2015.

Entre as soluções propostas pelo Banco Mundial para a resolução desse problema estão as mudanças na contratação de professores, facilitando o ingresso na carreira de profissionais não formados na área. $\mathrm{O}$ documento cita o trabalho Identifying effective teachers using performance on the job (2006), desenvolvido por Kane et al. No documento, aponta-se a centralidade do trabalho docente nas reformas educacionais. Segundo os autores,

\begin{abstract}
Nas duas últimas décadas, reformadores políticos têm buscado melhorar a qualidade da educação fundamental e média nos EUA. Visto que o sistema público de educação dos EUA tem se tornado um problema para o crescimento da produtividade e é uma das causas do aumento da desigualdade, tem-se buscado uma sucessão de reformas - de avaliações padronizadas a diminuição do tamanho das salas. Mas o sucesso do sistema público de educação nos EUA depende das habilidades de 3.1 milhões de professores nas salas de aula de escolas fundamentais e médias ao redor do país. Cada uma destas coisas - padrões educacionais, testes, tamanho das classes, quantificação - é o pano de fundo que suporta as cruciais interações entre os professores e os seus estudantes. Sem as pessoas certas na frente das salas de aula, a reforma escolar é um exercício fútil (KANE et al., 2006, p. 4).
\end{abstract}

Frente a esta centralidade, os autores defendem mudanças no processo de ingresso na carreira, indicando a redução de barreiras de entrada na profissão docente para aqueles sem certificação tradicional de professor. O controle se daria pela avaliação da eficiência dos novos docentes nos dois primeiros anos de carreira, sendo apenas efetivados nos cargos aqueles que fossem, comprovadamente, considerados eficazes. Para tanto, os autores apresentam uma equação quase ininteligível, com a qual poderia se medir, matematicamente, a eficiência 
dos professores. Após a efetivação dos docentes, as redes de ensino deveriam fornecer bônus para aqueles "altamente eficazes dispostos a ensinar nas escolas com elevada percentagem de alunos de baixa renda" (KANE et al., 2006, p. 32).

Pela proposta dos autores, a lógica de formação docente se reduziria a um treinamento que poderia, inclusive, ser feito de forma aligeirada. A forma de treinamento é apontada no documento do Banco Mundial de 2010, citando a experiência da organização não-governamental Teachers for all que tem, entre suas propostas, um curso de treinamento docente de quatro semanas para profissionais sem formação superior em Pedagogia ou Licenciatura. A ideia de permitir a entrada na carreira de profissionais não certificados implica em recusar as características próprias da formação e, consequentemente, intenso retrocesso na luta pela profissionalização docente.

Nesse processo, o currículo e as avalições padronizadas têm cumprido uma importante função de controle técnico do trabalho docente, como bem discutido por Michael Apple (2002) a partir da realidade estadunidense.

Com a utilização crescente de sistemas curriculares pré-empacotados, adotados como sendo a forma curricular básica, não é exigida virtualmente nenhuma interação por parte do professor. Se praticamente tudo é racionalizado e especificado previamente à execução, então o contato entre os professores a respeito de assuntos curriculares reais é minimizado (APPLE, 2002, p. 162).

O caso do currículo do Estado de São Paulo é emblemático: feito em três meses, no final do ano letivo de 2007, não contou com ampla participação dos professores da educação básica, sendo apresentada a eles no primeiro dia letivo do ano de 2008. Além de apostilas entregues aos alunos e às alunas, há um caderno didático distribuído aos docentes, demonstrando como eles devem trabalhar aula por aula. Há que se ressaltar que a tentativa de "convencimento" dos professores veio acompanhada de mecanismo de controle que articulam o desempenho dos estudantes, em avaliações padronizadas, às bonificações salariais pagas aos professores. Tais avaliações também não contaram com a participação dos docentes, sendo elaboradas ora por técnicos da Secretaria Estadual da Educação, ora por empresas privadas do ramo. Os conteúdos dessas avaliações estão referenciados no currículo oficial. Portanto, se o convencimento ideológico falhar, o controle técnico e burocrático fará o trabalho de garantir a adesão dos professores à reforma educacional proposta. 
Em documento mais recente, denominado "Professores Excelentes: como melhorar a aprendizagem dos estudantes na América Latina", o Banco Mundial reforça a concepção de avaliação pautada em currículos unificados e testes padronizados.

Um volume cada vez maior de dados de testes dos estudantes, particularmente nos Estados Unidos, que permite aos pesquisadores medir o valor agregado de cada professor no decorrer de um único ano letivo, gerou clara evidência dos diversos graus de eficácia dos professores, até na mesma escola e na mesma série. Os alunos com um professor mais fraco podem dominar $50 \%$ ou menos do currículo para aquela série: alunos com um bom professor têm um ganho médio de um ano; e estudantes com professores excelentes avançam 1,5 série ou mais (BM, 2014, p. 6).

Aqui encontramos um conceito-chave que nos ajuda a compreender a relação entre currículo unificado, testes padronizados e controle do trabalho docente: eficiência. Tal conceito tem norteado a quase totalidade das políticas mais recentes de educação para a América Latina com forte viés tecnicista e é uma das narrativas centrais nos documentos analisados neste artigo. A ideia de eficiência fomenta a busca por processos que reduzam investimentos e ampliem resultados em educação, quase todos medidos por testes padronizados. Para que o conceito de eficiência possa estar no centro de tais políticas que, como apontam o Banco Mundial, precisam reduzir os custos da Educação Pública, é preciso criar mecanismos que possibilitem a redução do conceito de qualidade, associando-a à aferição simples dos resultados em testes padronizados, como forma de criar um ambiente de contenção de gastos, como podemos verificar no trecho a seguir, retirado do documento de 2016, publicado pelo Instituto Airton Senna em parceria com a Fundação Santillana:

Mesmo que ainda haja margem para expandir os orçamentos educativos em alguns países, considerando o panorama econômico e fiscal menos positivo que a região enfrenta, de maneira geral, os sistemas educativos se verão obrigados a ser mais eficientes na destinação e no uso de recursos nos anos seguintes. Melhoras na eficiência, na distribuição e no uso de recursos devem ser um aspecto imprescindível para garantir a sustentabilidade dos esforços pela melhoria da qualidade educativa (INSTITUTO AIRTON SENNA, 2016, p. 32). 
Para se alcançar essa eficiência, todos os documentos analisados apontam a necessidade de que as políticas educacionais ampliem a relação entre os setores públicos e privados na gestão da educação pública. Há que se ressaltar que tal concepção já tinha sido apresentada nos debates travados e no documento final da Conferência Educação para Todos, ocorrida em Jointem, na Tailândia em 1991. Ali já aparecia a ideia de que, por conta dos problemas orçamentários, os países pobres deveriam focalizar os seus esforços na garantia do acesso da população ao ensino fundamental, realizando parcerias com a iniciativa privada para o oferecimento das outras etapas da educação. Essa ideia é reforçada no documento "La enseñanza superior", publicado em 1997, em que a defesa da privatização do ensino médio e do ensino superior são claramente explicitados.

No documento de 2010, o Banco Mundial retoma essa proposta, defendendo a necessidade, de um lado, de construir outros arranjos institucionais que possibilitem a cobrança de mensalidades nas universidades públicas; e, de outro, que sejam estabelecidas parcerias com o setor empresarial para mudanças curriculares no ensino médio. Essa proposição é retomada pelo documento de 2016, como podemos verificar a seguir:

Claramente, o custo desta expansão dependerá do esquema de financiamento adotado. Um modelo no qual a expansão de cobertura se baseie $100 \%$ em financiamento público demandará aumentos importantes no orçamento educativo e, em muitos casos, questionará a sustentabilidade financeira do sistema em sua totalidade. Por isso, esquemas de financiamento compartilhados, que envolvam uma mistura de taxas em instituições públicas, subsídios em instituições privadas e créditos, é uma resposta natural - em particular quando se considera o papel crescente das instituições privadas na prestação de serviços no segmento de educação superior (INSTITUTO AIRTON SENNA, 2016, p. 33).

Nos documentos analisados, o principal argumento utilizado para defender a contenção de investimentos e a ampliação das parcerias com o setor privado ${ }^{2}$ é o de que o Brasil alcançou, atualmente, os mesmos percentuais de investi-

2 Esta ampliação das parceiras com o setor privado tem se materializado, no caso do Ensino Médio, em programas como o Médio Tec., anunciado em março de 2017 pelo Ministério da Educação e que propõe oferecer 82 mil vagas em cursos técnicos, ao custo de 700 milhões de reais por ano, em projeto que retoma os princípios do Pronatec, que significou o repasse de um montante de recursos públicos para a iniciativa privada, para o oferecimento de cursos técnicos de qualidade bastante duvidosa. 
mento do PIB em educação dos países membros da OCDE. Tal argumento se constitui uma falácia porque desconsidera dois elementos essenciais: de um lado, o processo histórico de constituição da educação pública nos diferentes países e sua relação com a formação do estado nacional como garantidor de direitos sociais. De outro, o tamanho das redes de educação e do PIB de cada um desses países. Isso explica um dado com o qual os documentos analisados pouco dialogam: o investimento per capita por aluno é muito diferente entre o Brasil e os países da OCDE. Se levarmos em consideração o fato de estarmos distantes da construção de um Estado capaz de garantir os direitos sociais nas mais diferentes áreas, veremos a perversidade de uma proposta de diminuição ou de contenção dos investimentos em educação no Brasil e suas consequências em médio e longo prazo.

O foco do gerenciamento e controle do trabalho docente está bastante evidente no documento publicado pelo Banco Mundial em 2014. Segundo os autores, trata-se do resultado da observação de mais de 15 mil horas de aulas em toda a América Latina, o que possibilitou compreender as características de um professor eficiente. Segundo o documento, a eficiência docente passa pela gestão da sala de aula que resulta, diretamente, na melhoria da aprendizagem dos estudantes, conforme a Tabela 2, publicada no referido documento:

\section{TABELA 2 - USO DO TEMPO DE AULA NA QUINTA SÉRIE DAS ESCOLAS DO RIO DE JANEIRO, 2010}

\begin{tabular}{lcccc}
\hline & \multicolumn{4}{c}{ Uso do tempo de aula } \\
\cline { 2 - 5 } & $\begin{array}{c}\text { Tempo } \\
\text { com } \\
\text { instrução }\end{array}$ & $\begin{array}{c}\text { Organização } \\
\text { da sala de } \\
\text { aula }\end{array}$ & $\begin{array}{c}\text { Tempo } \\
\text { fora } \\
\text { de tarefa }\end{array}$ & $\begin{array}{c}\text { Professor fora da sala } \\
\text { de aula (incluído no } \\
\text { tempo fora de tarefa }\end{array}$ \\
\hline Município do Rio de Janeiro & $58 \%$ & $37 \%$ & $6 \%$ & $1 \%$ \\
\hline $10 \%$ melhores escolas no IDEB & $70 \%$ & $27 \%$ & $3 \%$ & $0 \%$ \\
\hline $\begin{array}{l}10 \% \text { piores entre as escolas } \\
\text { no IDEB }\end{array}$ & $54 \%$ & $39 \%$ & $7 \%$ & $3 \%$ \\
\hline Diferença & 0,16 & $-0,13$ & $-0,03$ & $-0,03$ \\
\hline & {$[0,09]^{*}$} & {$[0,09]^{*}$} & {$[0,02]^{*}$} & {$[0,01]^{* *}$} \\
\hline
\end{tabular}

FONTE: Banco de dados de observação em sala de aula do Banco Mundial.

NOTA: IDEB = Índice de Desenvolvimento do Ensino Fundamental. Erros significativos de padrão entre colchetes;

* estatisticamente importante no nível de 10\%; ${ }^{* *}$ estatisticamente importante no nível de 5\%.

Pela Tabela 2, é possível perceber a tentativa de estabelecer uma relação direta entre o tempo de exposição de conteúdos na sala de aula e as melhorias dos resultados do IDEB. Nesse processo, todas as outras dimensões que afetam a relação professor-aluno são desconsideradas, o que resulta em uma interpre- 
tação equivocada sobre a relação entre o trabalho docente e a aprendizagem discente. Estamos diante, nessa análise, daquilo que Azanha denominou de abstracionismo pedagógico:

Entendendo-se a expressão como indicativa da veleidade de descrever, explicar ou compreender situações educacionais reais, desconsiderando as determinações específicas de sua concretude, para ater-se apenas a "princípios" ou "leis" gerais que na sua abrangência abstrata seriam, aparentemente, suficientes para dar conta das situações focalizadas (2011, p. 42).

Na lógica do abstracionismo pedagógico, o contexto da prática educativa é negado, contribuindo na reprodução de uma lógica curricular unitária e que não respeita a autonomia e a diversidade que, em nossa perspectiva, são alguns dos fundamentos do trabalho educativo. Além disso, nessa lógica, o próprio currículo se apresenta como um objeto técnico-científico-informacional (SANTOS, 2014), construído em determinado contexto e por certos agentes sociais, cujas intencionalidades nunca estão plenamente evidentes para aqueles aos quais tal material foi direcionado.

No último documento analisado, publicado em 2015, em uma parceria entre a OCDE, o Instituto Airton Senna e a Fundação Santillana, o gerenciamento do trabalho docente está presente a partir do conceito de competências socioemocionais. $\mathrm{O}$ trecho a seguir apresenta algumas pistas para entendermos a origem do termo:

Quais são as competências que estimulam o bem-estar e o progresso social? Legisladores, incluindo 11 ministros e vice-ministros da Educação, discutiram essa questão na reunião ministerial informal da OCDE sobre "Competências para o Progresso Social" em São Paulo, Brasil, em 23 e 24 de março de 2014. Chegaram a um acordo unânime sobre a necessidade de desenvolver uma "criança completa" com um conjunto equilibrado de competências cognitivas e socioemocionais que lhe permitam enfrentar melhor os desafios do século 21. Pais, professores e empregadores sabem que crianças talentosas, motivadas, focadas em resultados e que agem colegiadamente são mais propensas a superar dificuldades, ter um bom desempenho no mercado de trabalho e, consequentemente, alcançar sucesso na vida (OCDE, 2015, p. 5). 
Resultado, portanto, de uma reunião organizada pela OCDE, em 2014, em parceria com o Instituto Airton Senna, o discurso das competências socioemocionais busca desenvolver, a partir das escolas, valores como foco nos resultados, na autoestima, na motivação, entre outros. É interessante perceber que tais valores estão na base dos principais manuais de administração capitalista, bem como no amplo conjunto de literatura de autoajuda vendido como best sellers nas principais livrarias do país. Mas o discurso das competências socioemocionais vai ainda mais longe:

O ambiente socioeconômico atual apresenta desafios que afetam o futuro das crianças e dos jovens. Embora o acesso à educação tenha melhorado, uma boa formação não é mais o único requisito para garantir um emprego; os jovens têm sido atingidos pelo crescente desemprego pós-crise econômica. Problemas como obesidade e diminuição do engajamento cívico crescem. O envelhecimento da população e o panorama ambiental preocupam. As desigualdades sociais e no mercado de trabalho tendem a aumentar. A educação tem enorme potencial para enfrentar esses desafios, melhorando competências. As competências cognitivas e as socioemocionais, como a perseverança, o autocontrole e a resiliência têm a mesma importância. É preciso incentivar todas as competências para indivíduos e sociedades prosperarem.

Nesse trecho, fica evidente a função central que o conceito deverá cumprir na escola, modificando o trabalho do professor. Na nova perspectiva, cabe à escola, através do professor, ajudar os alunos a formarem valores individuais que lhes permitirão competir em um mundo marcado pelas desigualdades. Nessa perspectiva, não se trata mais de possibilitar aos alunos e alunas, através da apropriação de conteúdos, conceitos, linguagens e instrumentos, o entendimento do mundo, com vista à superação de suas principais contradições, através de ações individuais e coletivas. Ao contrário, o objetivo é fazer com que os estudantes desenvolvam certos valores que interessam aos agentes do mercado de trabalho, fomentando a competição e ampliando a responsabilização dos sujeitos pelos seus sucessos e fracassos. As crises deixam de ser, nessa perspectiva, construções históricas, modificáveis, e passam a ser dados imutáveis da realidade.

A crítica ao discurso das competências socioemocionais não significa o desconhecimento da dimensão afetiva de toda relação educativa. Ao contrário, como aponta Paulo Freire (1992), a amorosidade se constitui como um dos elementos essenciais na construção da dialogia entre professor e aluno, mediados pelo mundo. No entanto, trata-se de superar uma lógica que reduz a afetividade 
ao domínio técnico-instrumental, que a encerra no campo individual, não compreendendo que é na alteridade, na relação com os outros que nos constituímos como sujeitos no/do mundo. Além disso, é preciso entender que essas relações que compõem os nossos afetos não se dão descoladas da realidade. São sempre contextualizadas, mediatizadas por projetos mais amplos de educação e sociedade, por políticas públicas, por ações em diferentes escalas espaço-temporais que modificam a nossa forma de ser, ver e sentir o mundo e os outros. Modificar os nossos afetos significa, portanto, modificar as nossas relações com o mundo e com o outro, o que se configura como ação coletiva, horizontal, solidária e de profunda responsabilidade.

Desse modo, a partir das análises, é possível compreender as diferentes dimensões que compõem a precarização do trabalho nas atuais reformas educacionais postas em prática no Brasil. É importante ressaltar que as análises apresentadas nos documentos vão na direção contrária daquelas apresentadas no $1^{\circ}$ Relatório de Acompanhamento do Plano Nacional de Educação, publicado em novembro de 2016, tanto no que se refere à questão dos investimentos, quanto à questão da demanda por educação pública. Talvez o dado mais preocupante, com o qual nenhum desses documentos dialoga, é o fato de que existam 1.650 .602 jovens de 15 a 17 anos que ainda não são atendidos no ensino médio, conforme o relatório (INEP, 2016). Em uma política educacional comprometida com a garantia do direito da educação para todos, a constatação dessa realidade seria motivo para a construção de mecanismos de ampliação dos investimentos para que todos os sujeitos pudessem ser plenamente atendidos em suas demandas. No entanto, quando o foco é construir uma política educacional que garanta as condições de reprodução de privilégios, a precarização das condições educativas já insuficientes se torna uma meta, como demonstrado em todos os documentos analisados.

\section{Considerações finais}

Ao compreender os sujeitos e as intencionalidades presentes no atual ciclo de reformas educacionais no Brasil, verificando a intensa disputa pelo orçamento público que está em sua base, colocamo-nos o desafio de construir a luta em torno de um outro projeto de educação, que tenha como princípio a defesa de um sistema nacional de educação, equitativo, gratuito e de qualidade socialmente referenciada. Pensamos que as bases para a construção desse sistema foram lançadas com o Plano Nacional de Educação (2014-2024) e, por isso, a 
necessidade de defendê-lo para que suas metas sejam plenamente cumpridas, em especial no que se refere à ampliação dos investimentos públicos em educação pública. Lutar pelo PNE, em nossa perspectiva, significa resistir ao projeto de Estado e sociedade que está presente na Emenda Constitucional que limita os Investimentos Públicos, na reforma do Ensino Médio, e em tantas outras medidas que têm como único objetivo ampliar a desigualdade de condições e de oportunidades que marca a história deste país.

Além disso, em outra escala da luta, é preciso entender a escola e a sala de aula como territórios de disputa e de construção desse outro projeto de educação, mais horizontal, inclusivo, colaborativo. É preciso se contrapor à tentativa de reduzir a complexidade do trabalho docente apenas à sua dimensão técnica. $\mathrm{O}$ reconhecimento do trabalho docente como complexo, articulador da teoria e da prática, da ação e da reflexão, pressupõe lutar por processos formativos iniciais e continuados que garantam aos docentes as condições teóricas e objetivas para refletirem sobre o que fazem cotidianamente, entendendo as diferentes mediações necessárias para o desenvolvimento do processo de ensino-aprendizagem. Para isso, é preciso relembrar o que disse Paulo Freire na Carta aos Professores: o primeiro compromisso ético-político docente é estudar. A luta pela autonomia docente frente às inúmeras tentativas de controle sobre o seu trabalho, seja através dos currículos prescritivos, seja por meio das avaliações padronizadas, pressupõe o exercício da responsabilidade sobre a sua formação e a luta pela garantia das condições de investimento público para que ocorra de forma constante e cotidiana.

Reconhecer a sala de aula como lugar de confronto e de construção de outras narrativas, de disputa do senso comum, é uma das estratégias fundamentais para potencializar a nossa luta em defesa de um outro projeto de educação, contrário à lógica dos reformadores expressa nos documentos aqui analisados. Aos educadores, sempre deve interessar aquilo que acontece na sala de aula, pois há ali muita potência em forma de desejo, há muita angústia e espaço de construção coletiva, há muito conflito e possibilidade de reelaboração. Se de fato, a sala de aula não comportasse todo este potencial, não sofreria, a todo momento, tentativas de intervenção, seja através do "manejo tecnocrático", seja pelos discursos autoritários, como o do movimento Escola Sem Partido. Disputar a sala de aula, preenchendo-a com os nossos corpos, discursos e afetos é ação simultânea à ocupação das ruas e das praças, neste movimento que leva a escola para a rua e a rua para a escola.

Portanto, a aprovação da MP do Ensino Médio não pode significar a derrota de nossa constante defesa de uma escola pública efetivamente democrática, no acesso, na permanência, na construção de sentidos, significados, conhecimentos. 
Frente à hipocrisia das palavras, resta-nos a coragem da luta! E esta coragem nos faz seguir sempre.

\section{REFERÊNCIAS}

APPLE, M. Educação e poder. Porto Alegre: Artmed, 2002.

AZANHA, J. M. P. Proposta pedagógica e autonomia da escola. Cadernos de História e Filosofia da Educação, São Paulo, v. 2, n. 4, p. 11-21, 1998.

AZANHA, J. M. P. Uma ideia de pesquisa educacional. São Paulo: Edusp, 2011.

BRASIL. Lei 11.738/08. Regulamenta a alínea "e" do inciso III do caput do art. 60 do Ato das Disposições Constitucionais Transitórias, para instituir o piso salarial profissional nacional para os profissionais do magistério público da educação básica. Brasília, Diário Oficial da União, 16 de julho de 2008.

BRUNS, B.; LUQUE, J. Professores excelentes: como melhorar a aprendizagem dos estudantes na América Latina e no Caribe. Washington: World Bank, 2014.

BRUNS, B.; LUQUE, J.; EVANS, D. Achieving world class education in Brazil: the next agenda. Washington: World Bank, 2010.

CONTRERAS, J. A autonomia dos professores. Trad. Sandra Trabucco Valenzuela. São Paulo: Cortez editora, 2012.

FREIRE, P. Pedagogia da autonomia. Rio de Janeiro: Paz e Terra, 1992.

GORDON, R.; KANE, T. J.; STAIGER, D. Identifying effective teachers using performance on the job. Washington: The Brookings Institution, 2006.

INEP. $1^{\circ}$ Relatório de Acompanhamento do Plano Nacional de Educação (2014-2024). Brasília: INEP, 2016.

INSTITUTO AYRTON SENNA. Construindo uma educação de qualidade: um pacto com o futuro da América Latina/Comissão para a Educação de Qualidade para Todos. São Paulo: Instituto Ayrton Senna, 2016.

NUNES, P. de S. Reforma curricular na rede estadual de ensino de São Paulo: decorrências para a organização do trabalho em uma escola. 2014. Dissertação (Mestrado) - Faculdade de Filosofia, Ciências e Letras de Ribeirão Preto da USP, 2014.

ORGANIZAÇÃO PARA COOPERAÇÃO E DESENVOLVIMENTO ECONÔMICO (OCDE). Estudos da OCDE sobre competências - Competências para o progresso social: o poder das competências socioemocionais. OCDE - Organização para Cooperação e Desenvolvimento Econômicos. São Paulo: Fundação Santillana, 2015. 
PIOLLI, E.; HELOANI, J. R. M.; PIOLLI, G. P. Z. A participação do setor empresarial nas politicas educacionais no estado de São Paulo (Brasil) e suas implicações no trabalho docente. Cidade do México: XI Seminário Internacional de la Red Estrado, 2016. SANTOS, M. A natureza do espaço. São Paulo: Edusp, 2014.

Texto recebido em 20 de julho de 2017. Texto aprovado em 12 de fevereiro de 2018. 